\title{
Cefalea por Hipotensión del Líquido Cefalorraquídeo
}

\author{
Amparo Rodríguez de Castro ${ }^{a}$, Javier Miñambres Mateos ${ }^{b}$, \\ José Tello Martínez ${ }^{c}$, Cristina Tello Fustel ${ }^{d}$,
}

\begin{abstract}
a Médico del Centro de Salud de Ossa de Montiel (Albacete).
\end{abstract}

${ }^{\mathrm{b}} \mathrm{A}$. Enfermería del Complejo Hospitalario Universitario de Albacete.

${ }^{c}$ A.T.S. del Centro de Salud de Ossa de Montiel (Albacete)

${ }^{d}$ A.T.S. Área de Salud de Toledo.

\section{Correspondencia:}

Amparo Rodríguez de Castro. Centro de Salud Ossa de

Montiel. Trav. Ramón y Cajal, s/n, 02611-Ossa de Montiel (Albacete). Telf.: 926528060 , e-mail: jampa@ono.com

Recibido el 18 de abril de 2008.

Aceptado para su publicación el 17 de mayo de 2008.

\section{RESUMEN}

El síndrome de hipotensión intracraneal se caracteriza por la presencia de cefalea postural asociada a una baja presión del líquido cefalorraquídeo (LCR). Según los criterios de la International Headache Society (IHS, 1988), la cefalea por disminución de la presión del líquido cefalorraquídeo es aquélla que aparece o empeora en menos de 15 minutos al ponerse el paciente en bipedestación y desaparece o mejora en menos de 30 minutos al volver a la posición supina. Presentamos el caso de un paciente varón de 34 años de edad con Hipotensión Intracraneal Secundaria.

Palabras clave. Hipotensión Intracraneal, Cefalea.

\section{ABSTRACT}

Headache from hypotension of cerebrospinal fluid

Intracranial hypotension syndrome is characterised by the presence of postural headache associated with low pressure of the cerebrospinal fluid (CSF). According to the criteria of the International Headache Society (IHS, 1988), headache caused by reduced cerebrospinal fluid pressure is that which appears or worsens in less than 15 minutes after the patient stands up and disappears or improves in less than 30 minutes after the patient lies down again. We contribute the case of a 34-year old male patient with Secondary Intracranial Hypotension.

Key words. Intracranial Hypotension, Headache.

\section{INTRODUCCIÓN}

El síndrome de hipotensión intracraneal es una entidad esencial o, más frecuentemente, secundaria. Se caracteriza por la presencia de cefalea postural asociada a una baja presión del líquido cefalorraquídeo (LCR). En humanos la presión media del líquido cefalorraquídeo es de $150 \mathrm{mmH}_{2} \mathrm{O}$, con un rango de 65 a $200 \mathrm{mmH}_{2} \mathrm{O}$ en decúbito lateral. Los síntomas de hipotensión intracraneal ocurren con presiones por debajo de $65 \mathrm{mmH}_{2} \mathrm{O}$.

El cerebro se sostiene en la cavidad craneal gracias a que flota sobre el LCR, ejerciendo éste una función de flotador, de tal manera que el peso del cerebro en aire es de $1.500 \mathrm{~g}$ y en LCR de tan solo $50 \mathrm{~g}$. Por tanto, si disminuye el volumen del LCR, el cerebro desciende retrocaudalmente y, por consiguiente, arrastra consigo estructuras sensibles al dolor, en especial los nervios craneales V, IX y X y las tres primeras raíces cervicales. Este descenso es más evidente en la postura de bipedestación por el efecto de la gravedad, y por ello empeora la cefalea.

En la hipotensión intracraneal la cefalea es un síntoma muy constante, más que en la hipertensión. Según los criterios de la International Headache Society (IHS, 1988), la cefalea por disminución de la presión del líquido cefalorraquídeo es aquélla que aparece o empeora en menos de 15 minutos al ponerse el paciente en bipedestación y desaparece o mejora en menos de 30 minutos al volver a la posición supina.

La Hipotensión Intracraneal se puede clasificar en:

1. Espontánea: sin evidencia de fuga o enfermedad sistémica.

2. Sintomática: tras punción lumbar (diagnóstica, mielografía, anestesia), traumática (craneal o espinal), posquirúrgica (craneotomía, cirugía espinal, post-neumonectomía), shunt de LCR malfuncionante, licuorrea, tumor hipofisario, enfermedad sistémica (deshidratación, coma diabético, hiperpnea, meningoencefalitis, uremia, infección sistémica). 
La Cefalea Postural Espontánea no se asocia a ninguna de las entidades anteriores y se considera que prácticamente todos los casos de Hipotensión Intracraneal Espontánea (HIE) son provocados por disminución de la producción de LCR, aumento de la absorción de LCR o fuga de LCR por una fisura de la duramadre oculta. Probablemente ésta última sea la principal causa de HIE y pudiera estar en relación con traumatismos menores que una anamnesis dirigida suele recoger y justificar dicho desgarro, como caer sentado, el coito, orgasmo, salvas de estornudos o tos, ejercicio vigoroso, etc.

La Cefalea Postural Secundaria a baja presión intracraneal es un cuadro conocido en la práctica neuroquirúrgica. Ésta frecuentemente sigue a una punción lumbar, craneotomía, cirugía espinal o traumatismo (craneal o espinal) y se suele asociar con otorrea y rinorrea. La cefalea post-punción aparece hasta en un $40 \%$ de los pacientes, más en mujeres jóvenes y con poco peso, y raramente en adultos mayores de 60 años. Su causa es la pérdida de LCR a través del orificio causado por la aguja de punción y no hay evidencia de que medidas como el reposo o la hidratación adecuada disminuyan la cefalea. Lo único que se ha demostrado eficaz en algunos estudios es la utilización de agujas de menor diámetro.

En principio, no suele requerir exploraciones complementarias ni tratamientos específicos. El diagnóstico de sospecha de la hipotensión intracraneal es fácil cuando la clínica es obvia y el factor desencadenante es fácilmente reconocible, sin embargo, cuando no es evidente ese factor desencadenante se debe recurrir a la realización de pruebas complementarias.

Si no hay antecedentes de punción lumbar se debe confirmar esa hipotensión licuoral mediante punción lumbar y medir la presión del LCR. Demostrada la hipopresión, la cisternografía isotópica puede ser útil para identificar el lugar por donde se produce la pérdida. La TC postmielografía es más sensible, pero hay que obtener múltiples cortes a lo largo de todo el canal vertebral. La Resonancia Magnética es una técnica sensible para localizar la fuga del LCR, pero su valoración ha de hacerse en conjunto y considerando la clínica del paciente.

El tratamiento se debe iniciar con medidas conservadoras, como el reposo en cama, ya que muchos pacientes mejoran espontáneamente; si no es así, se pueden intentar tratamientos farmacológicos como cafeína, teofilina, ergotamina, corticosteroides, ACTH, o bien parches epidurales de sangre autóloga o dextrano.

\section{OBSERVACIONES CLÍNICAS}

Se trata de un paciente varón de 34 años de edad que trabaja en el sector de la construcción y no tiene antecedentes personales de interés. En marzo de 2004 inició un cuadro de dolor lumbar bajo de características mecánicas, irradiado a miembro inferior izquierdo hasta pantorrilla, con estática y deambulación normales, ROT aquíleo izquierdo disminuido, sin déficit neurológicos y Lasègue izquierdo a $60^{\circ}$ y Bragard positivos, que no mejora con tratamiento médico. Practicada RMN, informan de hernia discal lateralizada a la izquierda en el segmento L5 - S1, con afectación radicular izquierda.

En su mutua inician tratamiento fisioterápico sin mejoría subjetiva, por lo que programan infiltración epidural. Tras la fisioterapia y tres infiltraciones, presenta mejoría subjetiva, tirantez ocasional, con fuerza muscular conservada y sin dolor espontáneo, por lo que inicia su actividad habitual.

En abril de 2007 acude a consulta con los mismos síntomas que en 2004. Tras tratamiento conservador sin mejoría y ante una nueva RMN que mantiene el diagnóstico de "Hernia discal extruida L5-S1", se remite a neurocirugía. En dicho Servicio se programa intervención quirúrgica, que se realiza en octubre del 2007, practicándose, bajo anestesia general, hemilaminectomía y flavectomía izquierda con buena evolución post-quirúrgica.

Tras siete días de la intervención y ya en su domicilio, consulta en dos ocasiones en urgencias del centro de salud por cefalea fronto-occipital derecha que él refiere como extraña pues mejora en la cama. Es tratado con corticoide intramuscular y tramadol y se tranquiliza al paciente relacionándola con la intervención quirúrgica. De nuevo consulta porque efectivamente ha comprobado que la cefalea empeora a los pocos minutos de levantarse de la cama o del sofá, ha notado alguna vez sensación de mareo, nauseas, sudoración profusa y molestias a la movilización del cuello, mejorando cuando vuelve a acostarse. Él cree que no debe guardar reposo pues tiene que iniciar el ejercicio después de su intervención, pero la cefalea le impide hacerlo. En la exploración clínica sólo se aprecia contractura paravertebral derecha con movilidad completa, sin focalidad neurológica y constantes dentro de la normalidad.

Se diagnostica como Cefalea por Hipotensión Intracraneal Secundaria, a pesar de no haber constancia de punción lumbar, ya que se realizó la cirugía bajo anestesia general; se inicia tratamiento conservador con reposo en decúbito y cafeína con ergotamina cada 8 horas, presentando mejoría sintomática a los 8 días del tratamiento, aunque no completa. En revisión por neurocirugía, al mes de la intervención, le realizan RMN en la que se informa de un pequeño meningocele posterolateral izquierdo, una pequeña cicatriz peridural posterolateral izquierda y un pequeño fragmento de disco protuido hacia atrás y hacia la izquierda. La clínica de la cefalea prácticamente ha desaparecido por lo que no se procede a otra terapéutica para reparar la lesión, se le recomienda la deambulación paulatina y el inicio de rehabilitación tres meses después de la cirugía.

Actualmente el paciente sigue en rehabilitación y sólo refiere algún episodio de cefalea leve que parece no estar en relación con el Síndrome de Hipotensión Intracraneal secundario a la cirugía espinal. 

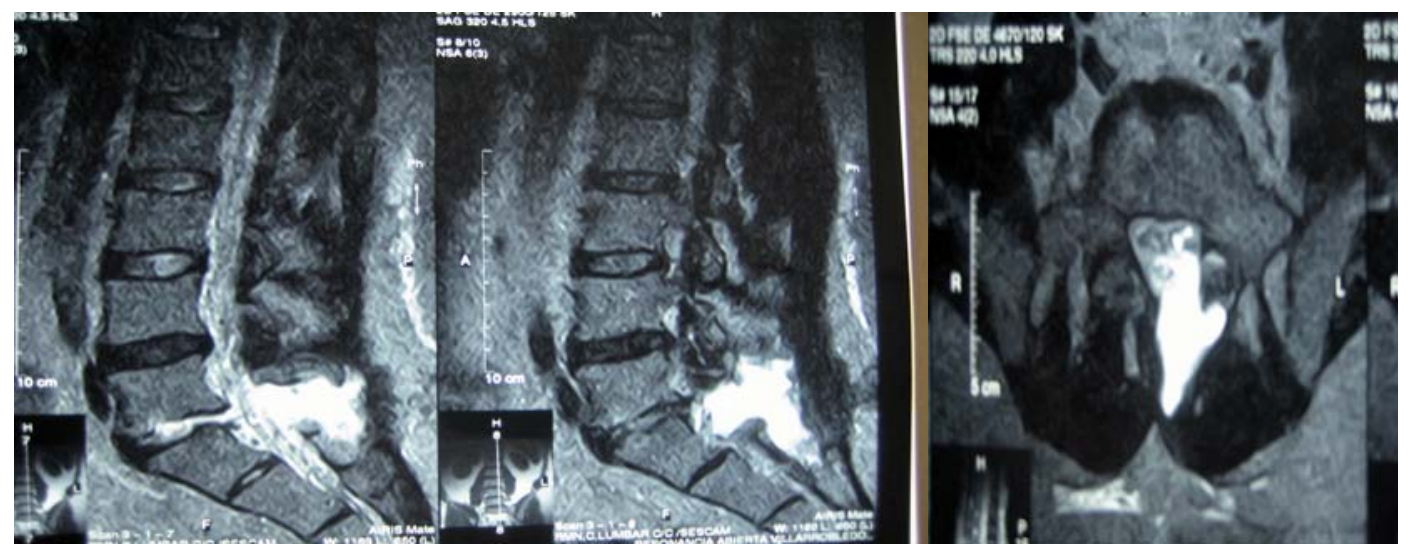

Figura 1. Hallazgos en RMN.

\section{DISCUSIÓN}

La incidencia real de la cefalea por hipotensión intracraneal es desconocida, ya que la cefalea es un síntoma muy común y, como la exploración física habitualmente es normal, el síndrome puede pasar desapercibido.

Conviene resaltar el interés de la postura en relación con la cefalea. Si ésta se presenta o se agrava al estar acostado, puede ser debida a un Síndrome de Hipertensión Intracraneal y cuando, por el contrario, aparece con la bipedestación y típicamente mejora con el decúbito habrá que pensar en la posibilidad de que nos encontremos frente a un Síndrome de Hipotensión Intracraneal.

La importancia de su reconocimiento radica en los errores diagnósticos que se pueden cometer ante un cuadro semejante y el excelente pronóstico del mismo.

\section{BIBLIOGRAFÍA}

1. Aguado Valcárcel M. Cefalea por Hipotensión Intracraneal. Boletín de la SGN 2002; 1(2). Disponible en: http://www. sociedadegalegadeneuroloxia.org/boletin2.htm\#facial.

2. Prat Rojo J. Curso de Cefaleas, Capítulo 19. Disponible en: http://profesional.medicinatv.com/fmc/cefaleas/cefalea19.

3. Benito-León J, Reina MA, Álvarez-Linera J. El síndrome de hipotensión intracraneal. Neurología 2001; 16:418-26.

4. Rocamora R, Carmona H. Hipotensión intracraneana espontanea. Cuadernos de neurología 1999. Disponible en: http://escuela.med.puc.cl/paginas/publicaciones/Neurologia/cuadernos/1999/pub_17_99.html. 